\title{
Silicon Metal-Oxide-Semiconductor Solar Cells with Oxide Prepared by Room Temperature Anodization in Hydrofluosilicic Acid Solution
}

\author{
Chih-Hao Chen, Chao-Chi Hong, and Jenn-Gwo Hwu ${ }^{\mathrm{z}}$ \\ Department of Electrical Engineering, National Taiwan University, Taipei, Taiwan
}

\begin{abstract}
It had been reported that liquid-phase deposition (LPD) using saturated hydrofluosilicic acid $\left(\mathrm{H}_{2} \mathrm{SiF}_{6}\right)$ is $\mathrm{useful}$ for silicon metal-oxide-semiconductor (MOS) solar cells. However, the LPD preparation time is long. In this work, anodic oxidation in saturated $\mathrm{H}_{2} \mathrm{SiF}_{6}$ solution is proposed as an alternative method to grow the room temperature oxides for MOS solar cells. It was found that the oxide preparation time is reduced significantly without sacrificing the efficiency in comparison with that by the LPD method. The oxide prepared by anodization (ANO) in $\mathrm{H}_{2} \mathrm{SiF}_{6}$ was found to be deposition-like which is different from that by ANO in $\mathrm{H}_{2} \mathrm{O}$. The oxidation time is about 5 min for the ANO method, but it is up to $4 \mathrm{~h}$ for the LPD method to obtain about $50 \AA$ thick oxide. After adding intercathode semitransparent thin Al film between thick Al cathode lines, it is apparent that all performances of the solar cells are improved. The reliability and efficiency of solar cells can also be improved above the $200^{\circ} \mathrm{C}$, 5 min postmetalization annealing treatment, and a conversion efficiency of $9.5 \%$ is shown.

(C) 2002 The Electrochemical Society. [DOI: 10.1149/1.1475695] All rights reserved.
\end{abstract}

Manuscript submitted June 18, 2001; revised manuscript received January 7, 2002. Available electronically April 30, 2002.

Since the first silicon solar cell was fabricated by using a diffused p-n junction at Bell Laboratories in the early 1950s, the reduction of cost has been a primary incentive in solar cell fabrication. ${ }^{1}$ Cost reduction depends on the method of junction fabrication. It was reported that the simple deposited metal-semiconductor junction is very attractive. ${ }^{2}$ However, intimate contact metal-semiconductor solar cells reveal a serious deficiency resulting from the thermionic emission dark current in Schottky barrier junctions. It is possible to surmount this disadvantage by using a very thin insulator to separate the metal and semiconductor that yields metal-oxide-semiconductor (MOS) solar cells. ${ }^{3}$ The MOS solar cell has received attention because its cost is low. Generally, the insulator of MOS solar cells should be very thin $(2 \mathrm{~nm})$ so that the tunneling current can be large enough for applications. ${ }^{4}$ However, there are several issues that must be considered in ultrathin oxides such as the control of oxide thickness uniformity and the quality of oxide.

It had been reported that liquid-phase deposition (LPD) ${ }^{5,6}$ using saturated hydrofluosilic acid $\left(\mathrm{H}_{2} \mathrm{SiF}_{6}\right)$ could be used in the preparation method of the oxide of silicon MOS solar cells. ${ }^{7,8}$ The LPD method has advantages such as no exact control of oxide thickness, room temperature process, and low cost. In particular, the trapassisted tunneling ${ }^{9}, 10$ property of the LPD oxide is useful for solar cell applications. However, the LPD preparation time is quite long.

In this work, anodization (ANO) in saturated $\mathrm{H}_{2} \mathrm{SiF}_{6}$ solution is proposed as a new method for preparing the room temperature oxides for silicon MOS solar cells. It is found that the oxide preparation time is reduced significantly without sacrificing the merits of the LPD method. Interestingly, it was found that ANO in $\mathrm{H}_{2} \mathrm{SiF}_{6}$ exhibits deposition-like oxide in current density-voltage $(J-V)$ characteristics. This oxide is similar to that of LPD and is useful for solar cell applications. Also, it was found that the ANO in $\mathrm{H}_{2} \mathrm{O}$ does not exhibit the above phenomenon.

It is known that the possible dark current mechanisms in a MOS solar cell can be described as ${ }^{11}$

$$
J_{\text {dark }}=J_{\mathrm{pt}}+J_{\mathrm{ps}}+J_{\mathrm{Dn}}+J_{\mathrm{rg}}
$$

where $J_{\mathrm{pt}}$ is the hole tunneling currents, $J_{\mathrm{ps}}$ is the hole current through interface traps, $J_{\mathrm{Dn}}$ is the diffusion current, and $J_{\mathrm{rg}}$ is the recombination generation current in the depletion layer. The net current drawn from the MOS solar cell can be written as

$$
J_{\mathrm{t}}=J_{\text {light }}-J_{\text {dark }}
$$

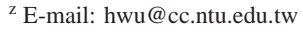

If the dark current $J_{\text {dark }}$ decreases substantially, the efficiency of the MOS solar cell will increase. For lower interface trap density, the surface-state current component $J_{\mathrm{ps}}$ is reduced which means that the dark current $J_{\text {dark }}$ becomes smaller. ${ }^{12}$ In order to increase the efficiency of the solar cell, the reduction of interface traps by using postmetalization annealing (PMA) is efficient. ${ }^{13}$ In addition, the PMA treatment is useful in stabilizing the number of traps in the oxide. After the PMA treatment the performance and reliability of the solar cell are improved significantly. Thus, the PMA treatment was performed on MOS solar cells in this work.

\section{Experimental}

The flowchart for preparing the saturated $\mathrm{H}_{2} \mathrm{SiF}_{6}$ solution and oxide formation is shown in Fig. 1. For over $3 \mathrm{~h}$ at $30^{\circ} \mathrm{C} \mathrm{SiO}_{2}$ powder was added to the $3.09 \mathrm{M} \mathrm{H}_{2} \mathrm{SiF}_{6}$ solution to saturate this solution, and then the saturated solution was filtered to separate the undissolved $\mathrm{SiO}_{2}$ powder. Deionized (DI) water was added to the filtered solution, and the ratio of the filtered $\mathrm{H}_{2} \mathrm{SiF}_{6}$ solution to DI water was $2: 1$. The $\mathrm{H}_{2} \mathrm{SiF}_{6}$ solution (saturated $\mathrm{H}_{2} \mathrm{SiF}_{6}: \mathrm{H}_{2} \mathrm{O}=2: 1$ ) was used to deposit the LPD oxide or as the electrolyte for the ANO method.

Boron-doped silicon (100) wafers with a resistivity of 1-10 $\Omega \mathrm{cm}$ were used as the substrate for MOS solar cells. We used platinum as the cathode plate and the $\mathrm{H}_{2} \mathrm{SiF}_{6}$ solution as the electrolyte. Anodizations were performed at various constant current densities. For comparison, the oxide prepared by the LPD method was also performed. The thickness of ANO and LPD oxides were measured by ellipsometry using a refractive index of 1.46. Then Al films with a thickness of about $200 \mathrm{~nm}$ were evaporated on oxides as the cathode. Al was selected to be the gate electrode because the process technology and theoretical derivations were well developed. ${ }^{7,11}$ Photolithography was carried out by using AZ1500 as the photoresist, ultraviolet light source, $300 \mathrm{~K}$ as the temperature of develop solution, and $\mathrm{H}_{3} \mathrm{PO}_{4}: \mathrm{HNO}_{3}: \mathrm{CH}_{3} \mathrm{COOH}: \mathrm{H}_{2} \mathrm{O}=85: 5: 5: 5$ solution as the $\mathrm{Al}$ etchant. The back oxide was etched off by a buffered oxide etchant (BOE). $200 \mathrm{~nm} \mathrm{Al} \mathrm{was} \mathrm{evaporated} \mathrm{on} \mathrm{the} \mathrm{back} \mathrm{silicon} \mathrm{sur-}$ face as the anode contact electrode. The intercathode semitransparent thin $\mathrm{Al}$ films with a thickness of $5 \mathrm{~nm}$ were then evaporated on the positive side of the wafer between cathode lines. The pattern and the cross section of solar cells is shown in Fig. 2a and b, respectively. Moreover, the solar cells without the intercathode thin Al films and with the films only on the active area of cell but not the entire wafer were also fabricated for comparison. In addition to MOS solar cells, MOS capacitors of $150 \times 150 \mu \mathrm{m}$ were also fabricated. In order to observe the effect of the PMA treatment on the 


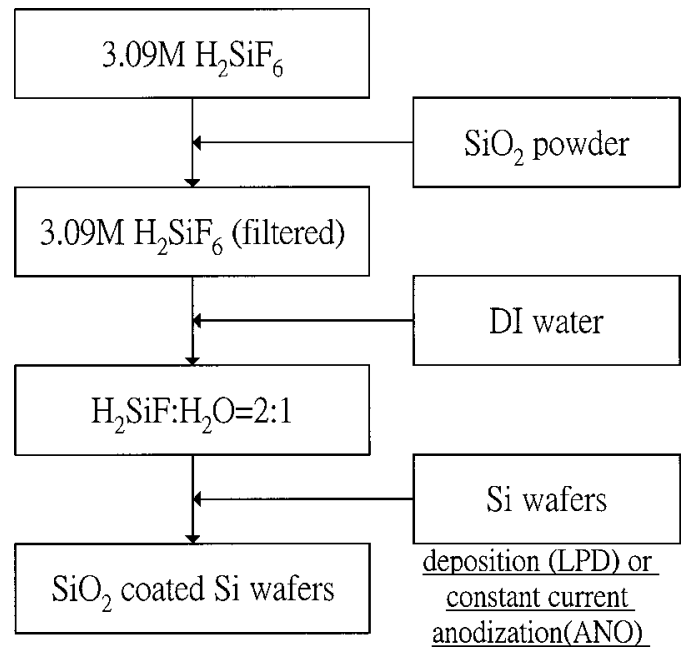

Figure 1. A flowchart showing the preparation of the saturated $\mathrm{H}_{2} \mathrm{SiF}_{6}$ solution and oxide formation.

performance of solar cells, different PMA temperatures and times were performed in $\mathrm{N}_{2}$ ambient, and then the efficiencies of solar cells were measured at different times. The $J-V$ characteristics of solar cells were measured under illumination using the Keithley measurement system, and the light source is a $100 \mathrm{~W}$ tungsten light bulb. For solar cell characterization a luminance intensity of 20 $\mathrm{mW} / \mathrm{cm}^{2}$ was employed.

\section{Results and Discussion}

Figure 3 shows the ANO oxide thickness $v s$. oxidation time with different constant current densities. The external electrical field can accelerate the rate of the oxide deposited on the Si substrate so that the oxidation time of the ANO method is much shorter than that of LPD method (see inset in Fig. 3). Besides, the ANO oxide thickness in pure water may be described as ${ }^{14}$

$$
d(t)=2.15(J t)^{1 / 2}+b
$$

where $d(t)$ is the time-dependent oxide thickness, $J$ is the ANO current density in microamperes per centimeter squared, $t$ is the growth time in minutes, and the constant $b$ is approximately nine for an oxide above $4 \mathrm{~nm}$ and three for an oxide below $4 \mathrm{~nm}$. From Fig. 3 it can be observed that under $0.01 \mathrm{~A} / \mathrm{cm}^{2}$ current density, it takes about $10 \mathrm{~min}$ to achieve $4 \mathrm{~nm}$ oxide thickness for ANO in $\mathrm{H}_{2} \mathrm{SiF}_{6}$. But in pure water, it takes about $30 \mathrm{~min}$, which can be evaluated from Eq. 3. An oxidation rate of $\mathrm{ANO}$ in $\mathrm{H}_{2} \mathrm{SiF}_{6}$ is much faster than that in pure water.

Figure 4a shows the $J-V$ characteristics of MOS capacitors with about $3 \mathrm{~nm}$ oxide prepared by LPD, ANO in $\mathrm{H}_{2} \mathrm{O}$, and ANO in $\mathrm{H}_{2} \mathrm{SiF}_{6}$ for a positive forward bias. The saturation phenomenon of the current is observed for oxides prepared by LPD and ANO in $\mathrm{H}_{2} \mathrm{SiF}_{6}$ but not by $\mathrm{ANO}$ in $\mathrm{H}_{2} \mathrm{O}$. It is believed that a leaky oxide cannot hold enough minority electrons in silicon because of its large tunneling leakage current. When the applied voltage is increased, the depleted region in the silicon must increase to meet the quantity of electric charges and thus the oxide is not easy to break down. The saturation current level is determined by the properties of silicon, e.g., interface trap density, bulk defect density, etc. ${ }^{12}$ It increases with increasing silicon surface damage due to more minority carriers being generated by defects. For an oxide prepared by ANO in $\mathrm{H}_{2} \mathrm{O}$, the bonds between $\mathrm{Si}$ and $\mathrm{O}$ are completely conjugated so that the penetrated oxygen seriously disturbs the silicon surface. This kind of oxide is used less for solar cell application in this work because its trap content is minimal. But for the deposited oxide, such as the LPD oxide, the silicon surfaces are less disturbed because of the

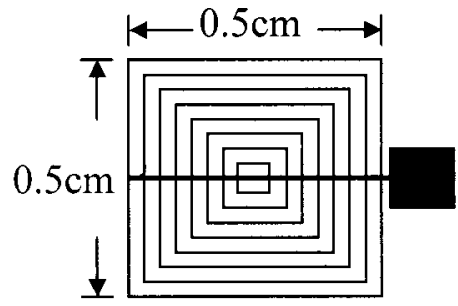

Total area $=0.25 \mathrm{~cm}^{2}$

Exposure area $=0.145 \mathrm{~cm}^{2}$

(a) Line width $=30 \mu \mathrm{m}$

Inter-cathode thin $\mathrm{Al}$

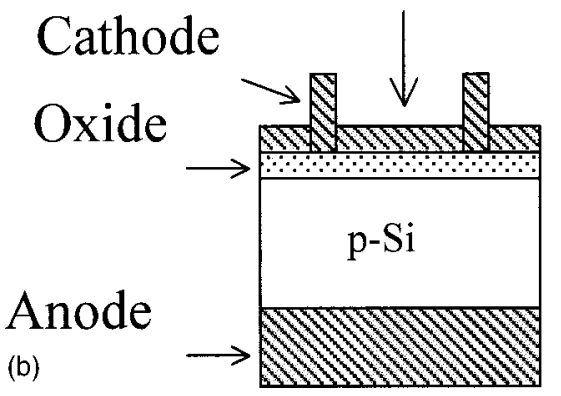

Figure 2. (a) Pattern and (b) cross section of silicon MOS solar cells.

weak $\mathrm{Si}-\mathrm{O}$ bond and the nature of deposited oxide. Therefore, the saturated current of LPD oxide is lower than that of an oxide prepared by ANO in $\mathrm{H}_{2} \mathrm{O}$. It is noted that the current behavior of an oxide prepared by ANO in $\mathrm{H}_{2} \mathrm{SiF}_{6}$ is similar to that of the LPD oxide. That is, the oxide prepared by ANO in $\mathrm{H}_{2} \mathrm{SiF}_{6}$ is similar in deposition but not growth due to the oxygen atoms penetrating in

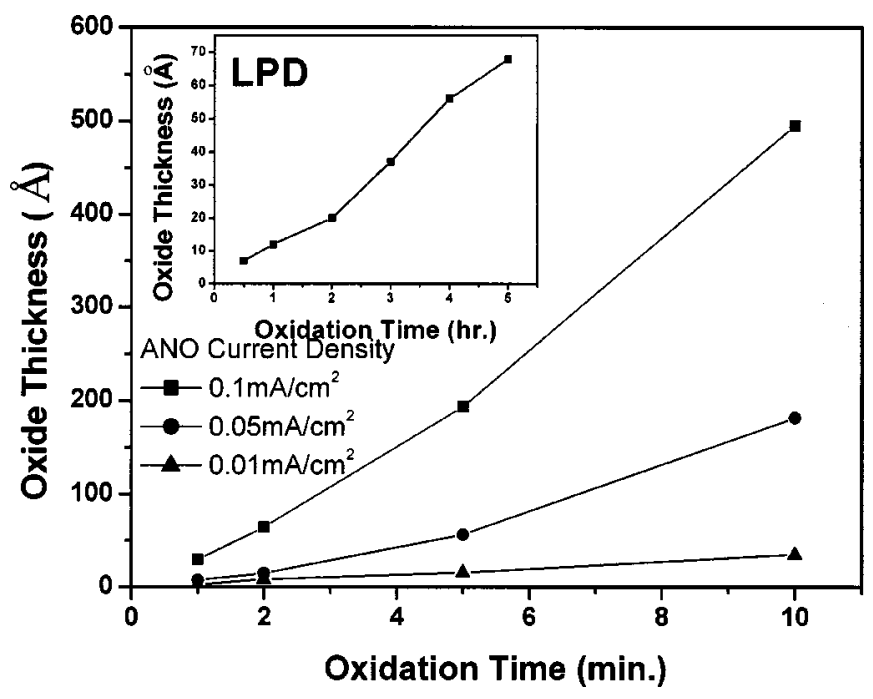

Figure 3. The ANO oxide thickness vs. oxidation time with different constant current densities. The inset shows oxide thickness $v s$. oxidation time for LPD. 

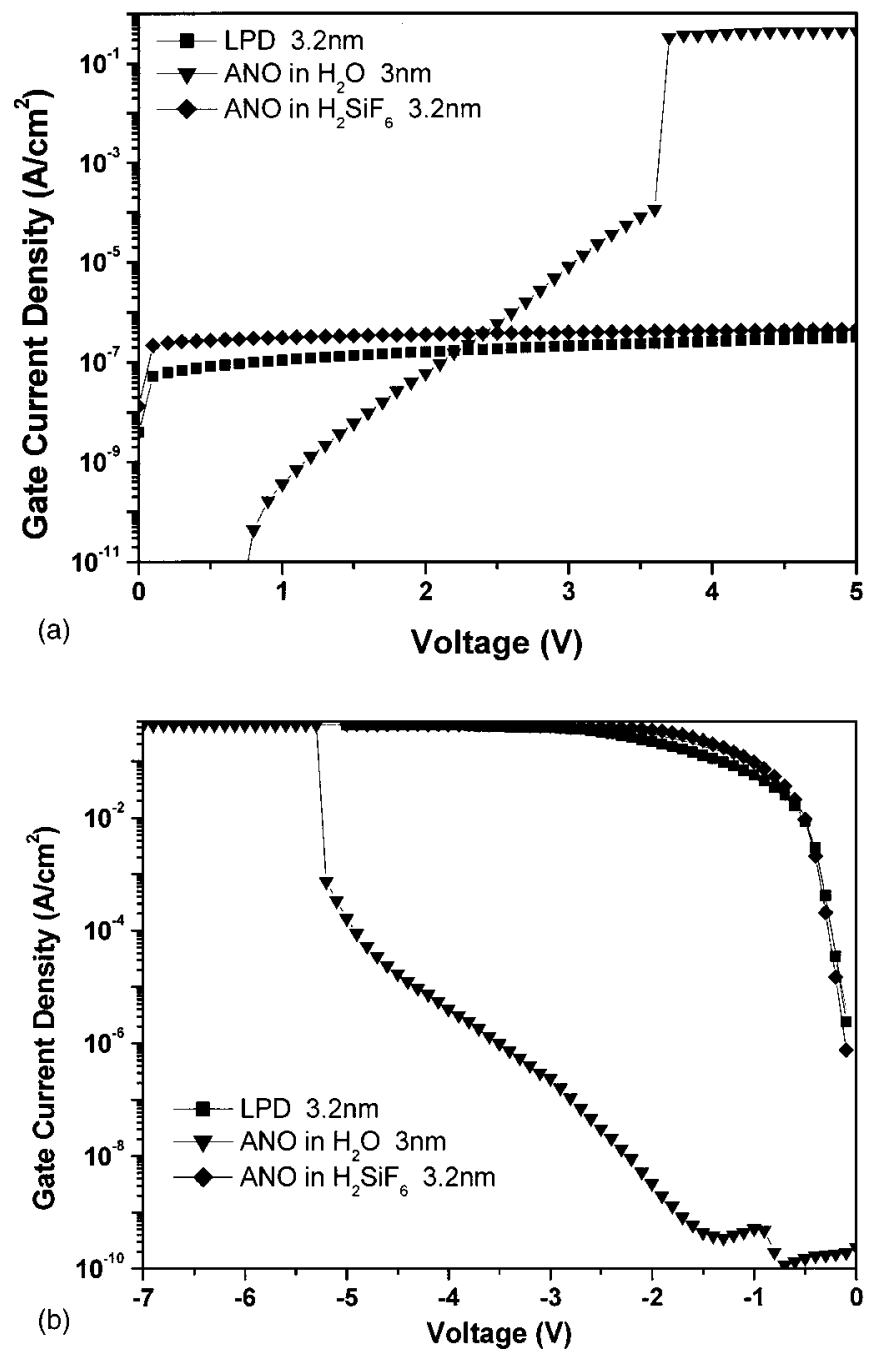

Figure 4. The $J-V$ characteristics of MOS capacitors with about $3 \mathrm{~nm}$ oxides prepared by $\mathrm{LPD}$, ANO in $\mathrm{H}_{2} \mathrm{O}$, and ANO in $\mathrm{H}_{2} \mathrm{SiF}_{6}$ for (a) positive and (b) negative bias.

the silicon surface to form $\mathrm{SiO}_{2}$. The $J-V$ curves under negative bias are depicted in Fig. 5b. Again, the properties of the oxide prepared by ANO in $\mathrm{H}_{2} \mathrm{SiF}_{6}$ are like those of the LPD oxide. ANO in pure water exhibits the direct tunneling phenomenon that belongs to a good oxide layer, ${ }^{15}$ but the tunneling current magnitude of ANO in $\mathrm{H}_{2} \mathrm{SiF}_{6}$ is much larger. It is supposed that the electrons tunneling through the ANO oxide do so also by way of trap-assisted tunneling, like the LPD oxide, which is useful for solar cell applications.

Figure 5a shows the $J-V$ curves of solar cells under illumination $\left(20 \mathrm{~mW} / \mathrm{cm}^{2}\right)$ with and without intercathode thin Al films for ANO. It was found that the solar cell performance is improved significantly in the appearance of increased open circuit voltage $\left(V_{\mathrm{OC}}\right)$, short-circuit current $\left(J_{\mathrm{SC}}\right)$ and fill factor after the intercathode thin Al films deposition. For solar cells without the intercathode thin Al films, many photogenerated electrons could be recombined before they are collected by the main electrode. The intercathode thin Al films can accelerate the collection of photogenerated electrons through the oxide and thus the performance of the solar cell parameters can be improved. ${ }^{7}$

In order to show that the intercathode thin $\mathrm{Al}$ films are thin enough so that even they are evaporated all over the entire wafer surface, the neighborhood cell effect due to parallel connections can be neglected, and the intercathode thin Al films outside the active area of solar cell are removed. Figure $5 \mathrm{~b}$ shows the $J-V$ curves of a
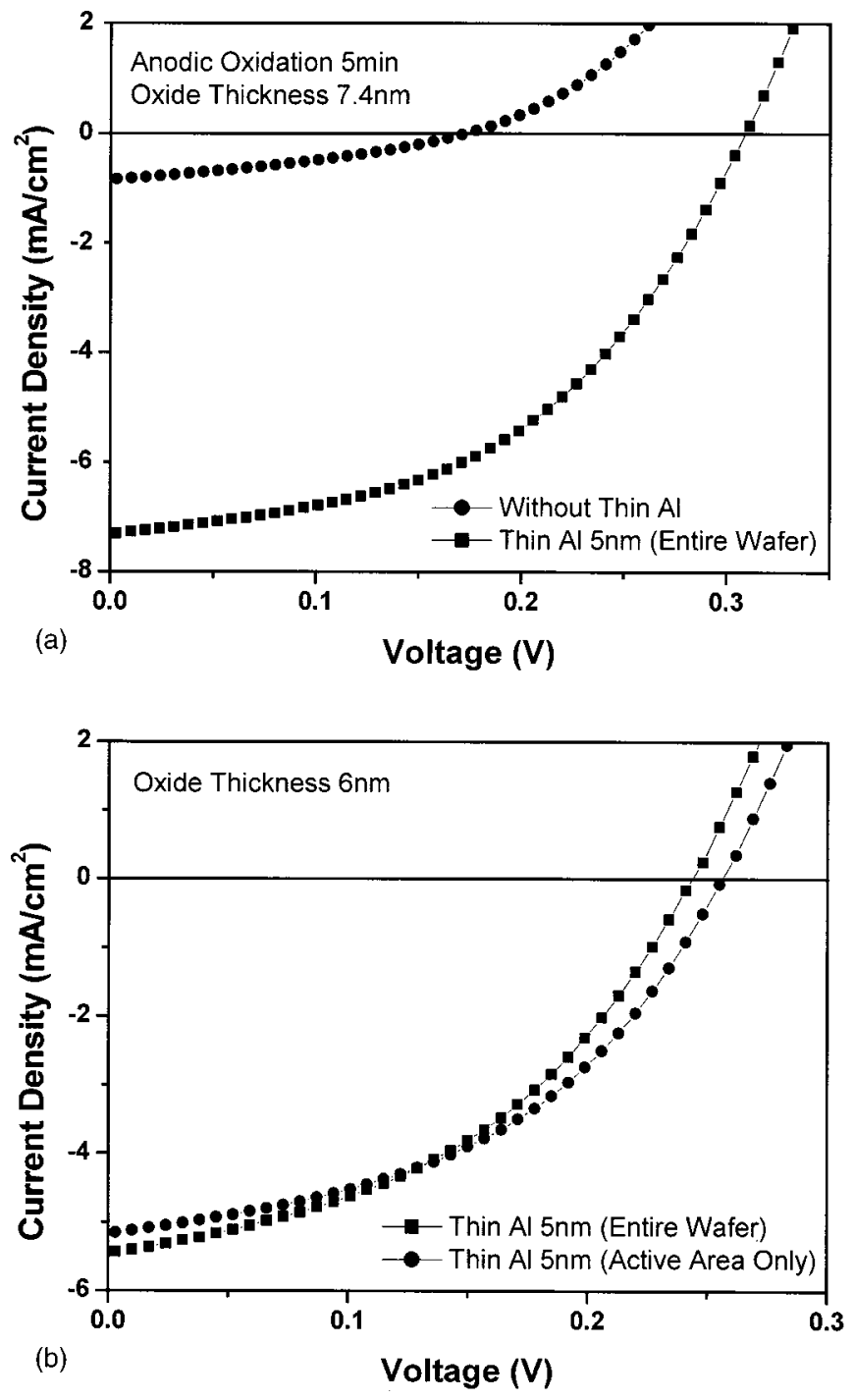

Figure 5. (a) The $J$-V curves of a solar cell under illumination (20 $\mathrm{mW} / \mathrm{cm}^{2}$ ) with and without intercathode semitransparent thin Al film for an oxide prepared by ANO. (b) The $J-V$ curves of a solar cell before and after etching the thin $\mathrm{Al}$ film outside the active area of device.

solar cell before and after etching the intercathode thin Al film outside the active area of the device. Their efficiencies are almost unchanged. Therefore, the neighborhood effect can be neglected in thin Al film deposition. The improvement of solar cell performance is mainly due to the direct collection of photogenerated electrons by the intercathode thin $\mathrm{Al}$ films.

Figure 6a shows the efficiency of solar cells before and after PMA for various temperatures, while the change ratios were shown in Fig. 6b. The efficiency was calculated with a consideration of the total area. The PMA time is fixed at $5 \mathrm{~min}$. The reduction of efficiency is observed for higher PMA temperatures $\left(>200^{\circ} \mathrm{C}\right)$. The values of efficiency even fall down to $0 \%$ when the PMA temperature is $400^{\circ} \mathrm{C}$ because the oxide is punched through by an $\mathrm{Al}$ spike. The cell $J-V$ curves before and after $400^{\circ} \mathrm{C}$ PMA are illustrated in Fig. 7. Al spiking leads to zero $V_{\mathrm{OC}}$, and thus zero efficiency is obtained. The efficiencies are improved at low PMA temperatures $\left(100-200^{\circ} \mathrm{C}\right)$. It is known that the PMA treatment is useful in reducing interface trap density. ${ }^{9,16}$ For a lower interface trap density, the surface-state current component is lower which means that the dark current becomes lower. Therefore, the solar cells with PMA treatment reveal larger total currents and efficiencies. 

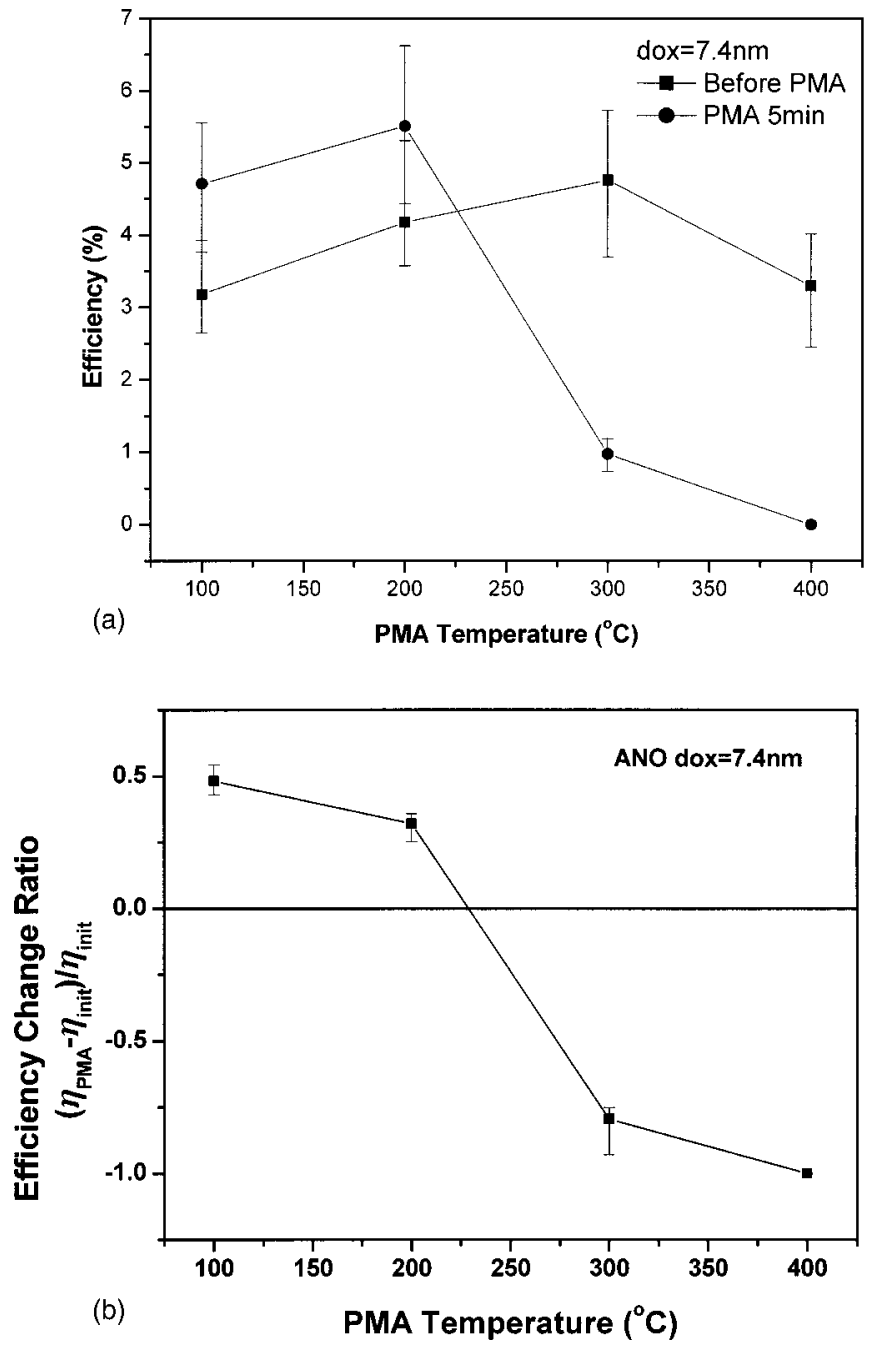

Figure 6. (a) The efficiencies of solar cells vs. PMA temperature. Those before PMA are also indicated in this figure. (b) The efficiency change ratios of solar cells $v s$. PMA temperature.

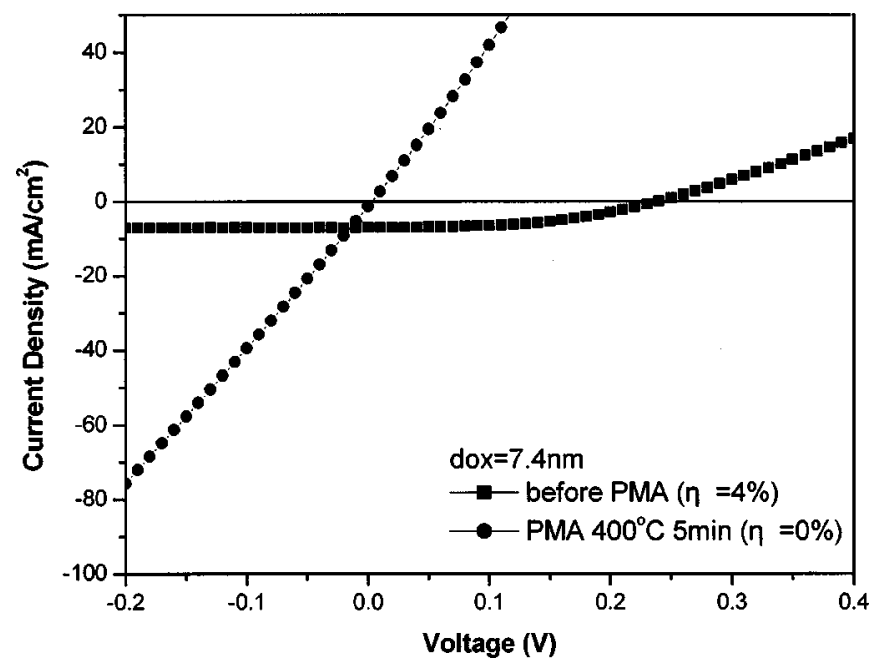

Figure 7. The $J-V$ curves of solar cells before and after $400^{\circ} \mathrm{C}, 5$ min PMA.

Figure $8 \mathrm{a}$ shows the solar cell efficiency before and after PMA under various times while the change ratios are shown in Fig. 8b. The PMA temperature is fixed at $200^{\circ} \mathrm{C}$. It was found that the efficiency decreases with increasing PMA time when the PMA time is
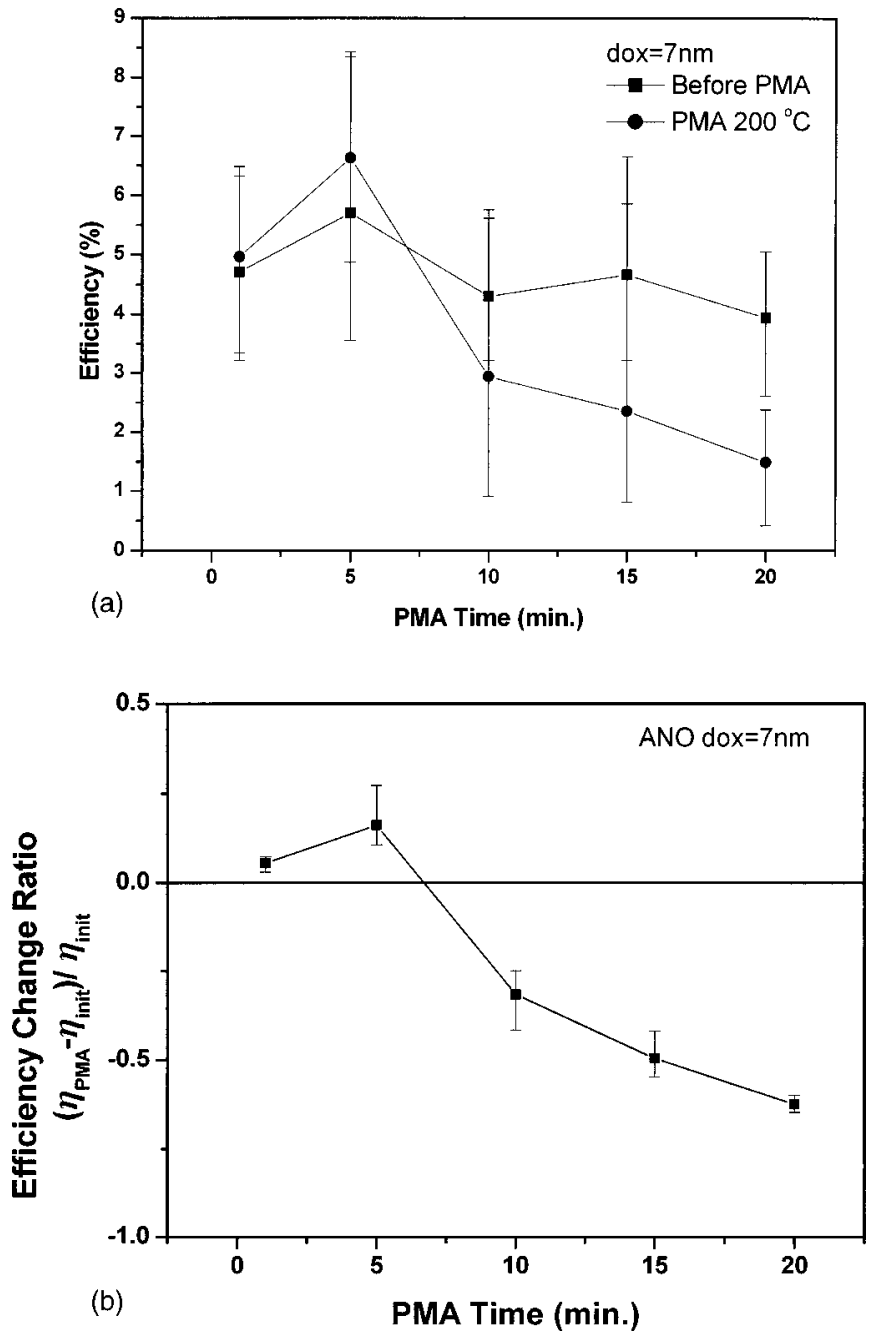

Figure 8. (a) The efficiencies of solar cells $v s$. PMA time for a PMA at $200^{\circ} \mathrm{C}$. Those before PMA are also indicated in this figure. (b) The efficiency change ratios of solar cells $v s$. PMA time.

greater than $5 \mathrm{~min}$. The efficiency increases apparently at the $5 \mathrm{~min}$ PMA time. It had been reported that the solar cells exhibit optimum performance under 7-8 nm deposition like oxide thickness and $5 \mathrm{~nm}$ intercathode thin $\mathrm{Al}$ film. ${ }^{7,17}$ In this work, the appropriate PMA conditions for improving efficiency were investigated, i.e., $200^{\circ} \mathrm{C}$ and 5 min, as concluded from the above discussion. An efficiency of up to $9.5 \%$ is obtained. The $J-V$ curves of one solar cell with an optimum performance before and after PMA are shown in Fig. 9. Both $V_{\mathrm{OC}}$ and $J_{\mathrm{SC}}$ increase after PMA treatment. This efficiency is quite attractive for real solar cell applications.

It had been mentioned above that the improvement of solar cell efficiency after PMA is mainly due to the reduction in interface density and thus the dark current. In order to provide more insight, conditions simulating the the dependence between dark current and interface density were simulated. Figure 10 shows the theoretical $J-V$ curves of MOS capacitors for different interface trap densities based on the equations in Ref. 12. The dark current indeed decreases with decreasing interface trap density. Some other studies also support this inference. ${ }^{18,19}$ It should be noticed that Fig. 10 only provides a qualitative description. The oxide thickness and minority carrier life time were held at $2 \mathrm{~nm}$ and $32.5 \mu \mathrm{s}$, respectively. The experimental data in Fig. 5a were measured on $3.2 \mathrm{~nm}$ oxide, and the actual minority carrier life time was unknown. The saturation current density around $10^{-7} \mathrm{~A} / \mathrm{cm}^{2}$ in Fig. 5a does not give a direct indication that the interface densities of LPD and ANO in $\mathrm{H}_{2} \mathrm{SiF}_{6}$ 


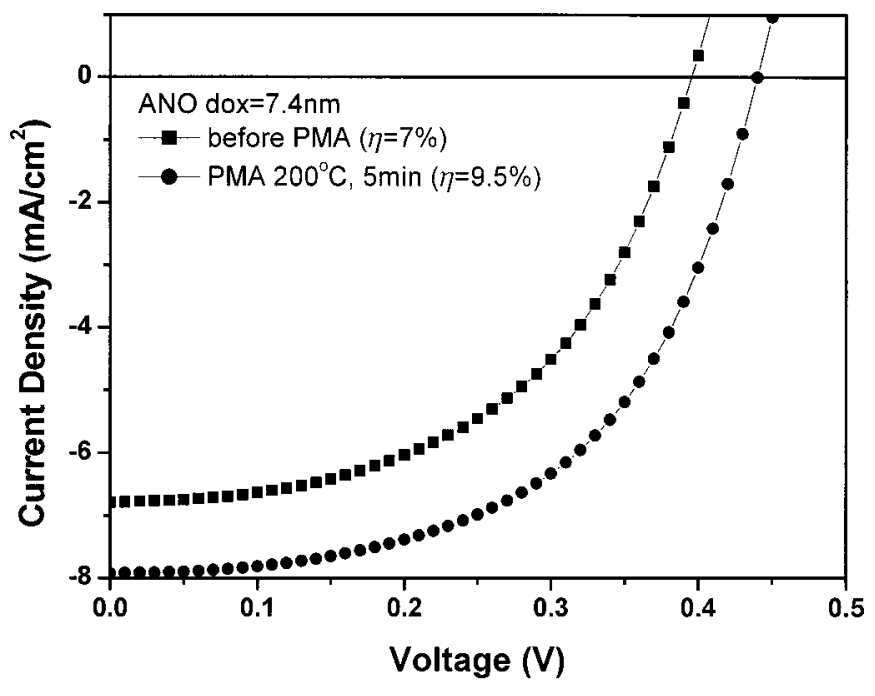

Figure 9. The $J-V$ curves of a solar cell before and after $200^{\circ} \mathrm{C}, 5 \mathrm{~min}$ PMA.

samples were about $3 \times 10^{12} \mathrm{~cm}^{-2} \mathrm{eV}^{-1}$, in comparison with Fig. 10. However, it is believed that the improvement of the performance of solar cells after PMA treatment is mainly due to the lower interface density.

Figure 11 shows the efficiency $v s$. room temperature anneal time for solar cells after 100 and $200^{\circ} \mathrm{C}$ PMA for $5 \mathrm{~min}$. Samples were kept in a moisture proof box in the dark, except when measurements were carried out. It was found that the efficiency degradation phenomenon is still serious at $100^{\circ} \mathrm{C}$ PMA. It is supposed that this phenomenon is probably because the number of the traps existing in the oxide varies with time. These traps are suggested to be fluorinerelated since ANO was carried out in $\mathrm{H}_{2} \mathrm{SiF}_{6}$, and the resulting oxide is LPD-like. However, degradation is much suppressed for $200^{\circ} \mathrm{C}$ PMA because the proper PMA treatment can stabilize the traps in the oxide.

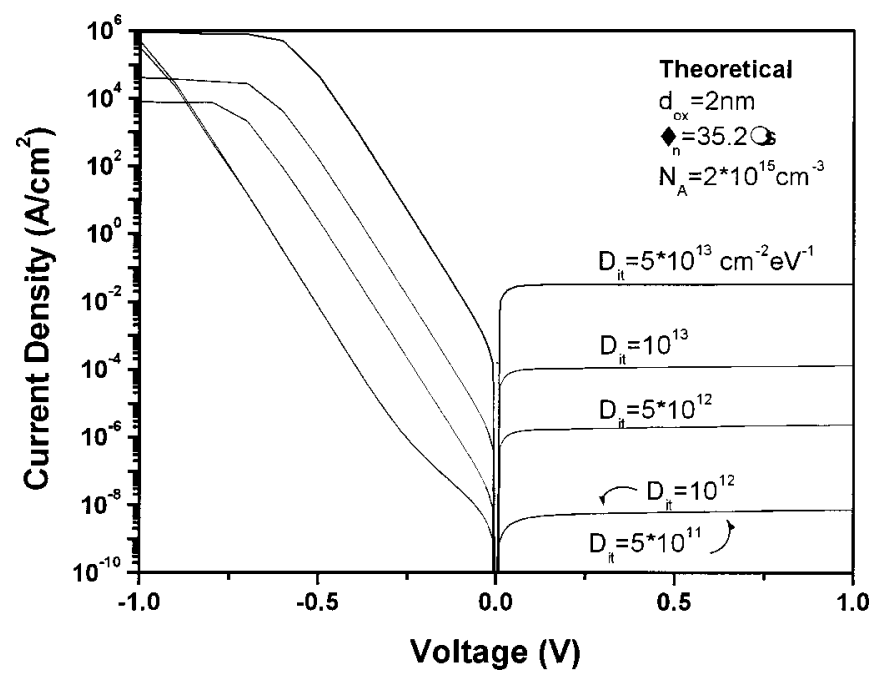

Figure 10. The theoretical $J-V$ curves of MOS capacitors with $2 \mathrm{~nm}$ oxide for different interface trap density $D_{\text {it }}$.

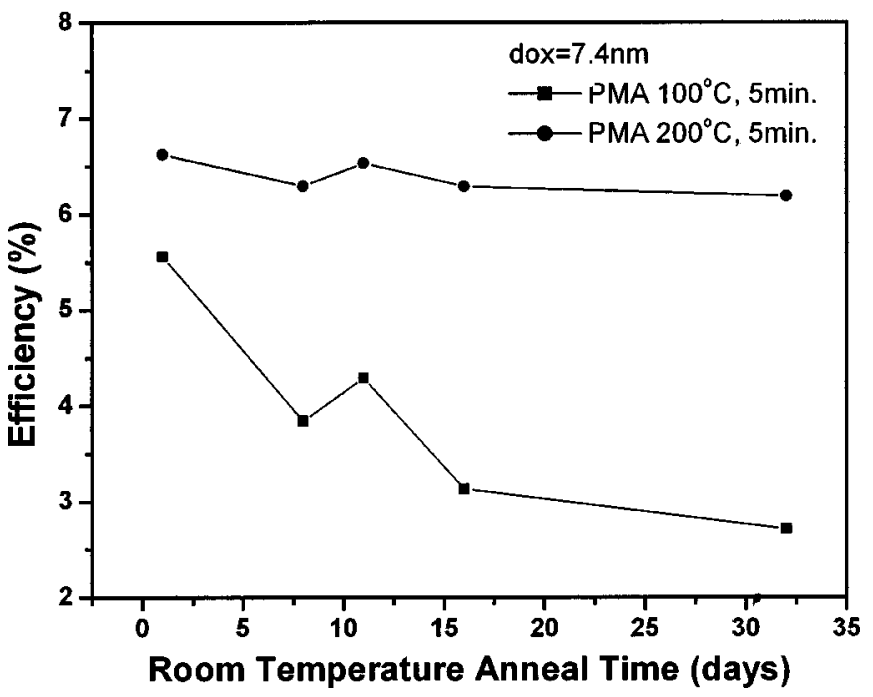

Figure 11. Efficiency $v s$. room temperature anneal time for solar cells after 100 and $200^{\circ} \mathrm{C}$ PMA for $5 \mathrm{~min}$.

\section{Conclusions}

Anodic oxidation in saturated $\mathrm{H}_{2} \mathrm{SiF}_{6}$ solution is proposed as an alternative method for growing room-temperature oxides for MOS solar cells. Oxide preparation time using the ANO method is significantly shorter than that using the LPD method. With the addition of intercathode thin Al films, the performance of solar cells can be much improved. The PMA treatment can improve not only reliability but also the efficiency of MOS solar cell. Under 7-8 nm ANO oxide thickness and $5 \mathrm{~nm}$ intercathode $\mathrm{Al}$ thickness, the suggested optimum condition of PMA is $5 \mathrm{~min}$ at $200^{\circ} \mathrm{C}$. After the PMA treatment an efficiency of up to $9.5 \%$ can be obtained. Nevertheless, the proposed new method for preparing an oxide used in Si MOS solar cell in this work is simple and cost effective.

\section{Acknowledgments}

The authors thank the National Science Council of Republic of China for supporting this work under contract no. NSC 90-2215E002-033.

National Taiwan University assisted in meeting the publication costs of this article.

\section{References}

1. A. Rohatgi, S. Narasimha, A. U. Ebong, and P. Doshi, IEEE Trans. Electron Devices, 46, 1970 (1999).

2. D. L. Pulfrey, IEEE Trans. Electron Devices, 25, 1308 (1978).

3. M. J. Keevers and M. A. Green, J. Appl. Phys., 75, 4022 (1994).

4. J. Shewchun, R. Singh, and M. A. Green, J. Appl. Phys., 48, 765 (1977).

5. C. F. Yeh, C. L. Chen, and G. H. Lin, J. Electrochem. Soc., 141, 3177 (1994)

6. C. F. Yeh, S. S. Lin, and C. L. Fan, IEEE Electron Device Lett., 16, 473 (1995).

7. K. C. Lee and J. G. Hwu, IEEE Electron Device Lett., 18, 565 (1997).

8. K. C. Lee and J. G. Hwu, J. Vac. Sci. Technol. A, 16, 2641 (1998).

9. M. Lenski, T. Endoh, and F. Masuoka, J. Appl. Phys., 88, 5238 (2000).

10. S. Takagi, N. Yasuda, and A. Toriumi, IEEE Trans. Electron Devices, 46, 348 (1999).

11. M. Y. Doghish and F. D. Ho, IEEE Trans. Electron Devices, 40, 1446 (1993).

12. M. Y. Doghish and F. D. Ho, IEEE Trans. Electron Devices, 39, 2771 (1992).

13. J. Camp, Y. Shi, Y. Luo, F. Yan, and J. H. Zhao, IEEE Trans. Electron Devices, 46, 511 (1999).

14. C. C. Hong, M. S. Thesis, National Taiwan University, Taipei, Taiwan (1998),

15. C. C. Ting, Y. H. Shih, and J. G. Hwu, IEEE Trans. Electron Devices, 49, 179 (2002).

16. T. Hori, Gate Dielectrics and MOS ULSIs: Principles, Technologies, and Applications, Springer-Verlag, New York, (1997).

17. Y. P. Shen and J. G. Hwu, IEEE Photonics Technol. Lett., 8, 420 (1996).

18. C. Y. Chang and S. J. Wang, Solid-State Electron., 29, 339 (1986).

19. A. Ghetti, E. Sangiorgi, J. Bude, T. W. Sorsch, and G. Weber, Tech. Dig. Int. Electron Devices Meet., 1999, 731. 